\title{
The Relationship Between Energy Consumption and Economic Growth: A Case Study of Shanghai
}

\author{
Zhang Yuhao \\ School of Economics, Shanghai University, Shanghai, China
}

\section{Email address:}

zhangyuhao1006@foxmail.com

\section{To cite this article:}

Zhang Yuhao. The Relationship Between Energy Consumption and Economic Growth: a Case Study of Shanghai. Science Innovation. Vol. 4, No. 6, 2016, pp. 259-266. doi: 10.11648/j.si.20160406.13

Received: October 24, 2016; Accepted: November 30, 2016; Published: December 5, 2016

\begin{abstract}
According to the data of Shanghai Statistical Yearbook, the relationship between total energy consumption and economic development of Shanghai is analyzed through the change of energy elasticity coefficient and energy consumption intensity. By using the method of gray relational analysis, the correlation between energy consumption structure and economic growth is explored, which provides a theoretical basis for promoting the coordinated development of energy consumption and economic growth. In addition, suggestions are made on the further development of Shanghai.
\end{abstract}

Keywords: Energy Consumption, The Energy Coefficient of Elasticity, Energy Consumption Intensity, Grey Correlation Analysis, Economic Growth

\section{能源消费与经济增长的关系- - 以上海市为例}

\section{张育豪}

经济学院, 上海大学, 上海, 中国

邮箱

zhangyuhao1006@foxmai1.com

摘要：根据《上海市统计年鉴》的相关数据, 通过能源弹性系数与能源消费强度的变化, 分析上海市的能源消费总量 与经济发展的关系。运用灰色关联分析方法, 探究能源消费结构与经济增长的相关性, 为促进能源消费与经济增长的 协调发展提供了理论依据,并且对上海的进一步发展提出建议。

关键词: 能源消费, 能源弹性系数, 能源消费强度, 灰色关联分析, 经济增长

\section{1. 引言}

能源自古以来就与社会的发展高度紧密联系在一起, 它是人类赖以生存和生活的重要原料来源, 也是社会进步 和历史发展的主要动力源泉。伴随着经济的迅猛发展, 能 源与经济之间的矛盾开始突显, 能源对经济的约束力也日 益显现, 能源与资源已经成为关系到经济能否持续健康发 展的重要物资 $[1]$ 。
中国自改革开放以来, 上海经济步入了持续、快速发 展的阶段, 全市地区生产总值增长速度连续高速增长。能 源有力地保障了上海市经济社会的稳定快速发展和人民 生活水平的不断提高。但由于该地域狭小、人口密集、自 然资源贵乏、能源消费集中等原因, 上海市政府在实施可 持续发展战略过程中一直面临着经济增长质量与增长方 式、资源与环境、消费与保护等问题的严峻挑战。因此找 
出能源与经济增长的关系, 有着十分重要的意义 [2]。研 究能源消费与经济增长之间的关系有以下几点原因:

(1) 了解能源对经济的关系不仅可以让我们更加深刻 地认识经济，而且还让我们正确树立的能源消费观 念。从而可以更高效地利用能源为我们的经济服务, 同时也可以让我们认识到能源的稀缺性，可以让我 们更好地保护日益减少的非再生能源。

（2）中国经济产业结构正面临着升级和转型的现实情 况。在中国经济处于工业化的中期阶段, 产业转型 和升级是企业不得不面临的选择, 如果仍然长期处 于低产出和高投入的产业阶段, 不仅企业难以在激 烈的竞争中生存而且整个国家的经济增长都会出 现缓慢甚至负面增长的局面, 甚至会导致中国步入 中等收入陷阱。上海作为中国经济的排头兵, 必须 处理好能源与经济增长的关系, 努力转变能源生产 结构和利用结构, 为中国探索出一条低能源消费与 快速经济增长并存的道路。

(3) 重视发展多种能源, 是促进和推广新型能源利用的 重要手段之一。对能源的深刻认识有助于帮助中国 严重依赖单一的能源, 可以根据各种实际情况发展 多种能源: 如风能、潮汐、生物能和水能等可再生 能源资源。

（4）同时也能增加社会保护环境的意识。环境是人们生 存和发展的依靠, 良好的生存生活环境是每个人追
求的目标之一。传统的化石能源虽然为人类的发展 提供了巨大的贡献，同时我们的物质生活水平也有 了飞速的提高, 但是化石能源也给环境带来了严重 的污染。因此, 研究能源与经济增长的关系不仅可 以为经济增长提供持续的资源同时也可以帮助人 们树立良好地环境意识, 从而达到人与自然和谐相 处。

\section{2. 上海能源的基本情况}

\section{1. 能源的增长支持了国民经济的较快发展}

能源的消费是拉动经济增长的重要因素, 社会经济 的快速发展也对能源消费有带动作用。上海市的地区生 产总值由 2004 年 8072.83 亿元增加到2013年的 21602.12 亿元, 年均增长速度 $10.3 \%$ 。同时上海市的能源消费总 量由 2004 年 7405.64 万 $\mathrm{t}$ 标准煤增加到 2013 年的 11703.67 万t标准煤, 年均增长速度为 $4.7 \%$ 。从 2003 年 至2007年上海市的能源保持了快速的增长, 07年到08年 是上海转变经济的一年, 但 2008 年随之而来的是由美国 引发的全球金融危机, 为刺激经济增长, 上海市又步入 了粗放型的经济增长, 但强度比以前有了下降, 从 08 年 至13年总的能源消费保持了平稳的增长, 总体来看上海 市的能源发展是与经济社会发展基本相适应的。

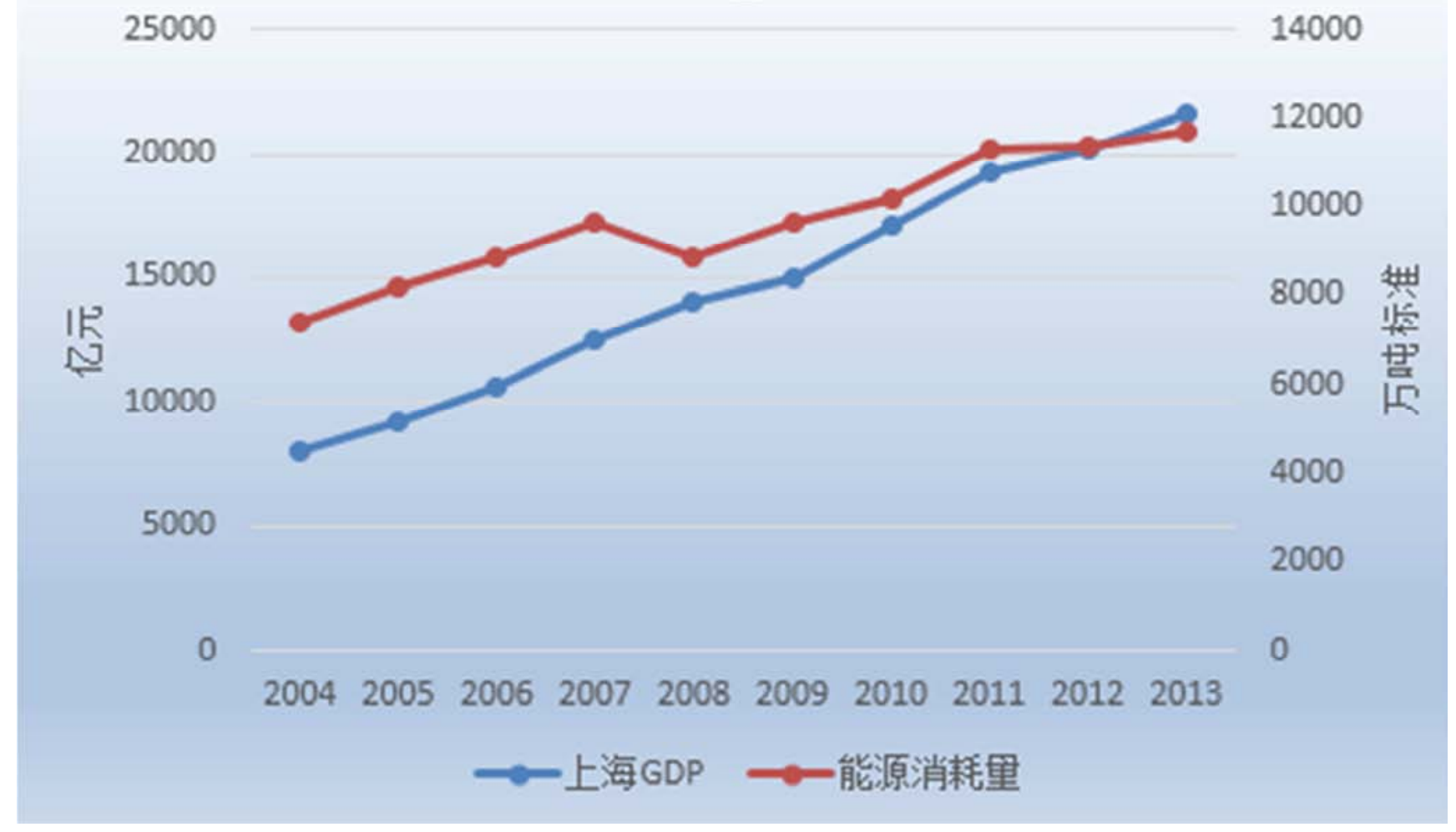

图1 2004-2013年上海GDP和能源消耗量。数据源于《上海统计年鉴》。

\section{2. 能源结构不断优化}

由下图可以看出, 上海一次能源消费总量呈增加趋势, 但增长速度趋于下降, 煤消费增长速度慢于石油消费增长 速度。说明上海一次能源消费结构不断优化，对于利用率低，污染排放严重的煤能源消费得到了控制。 


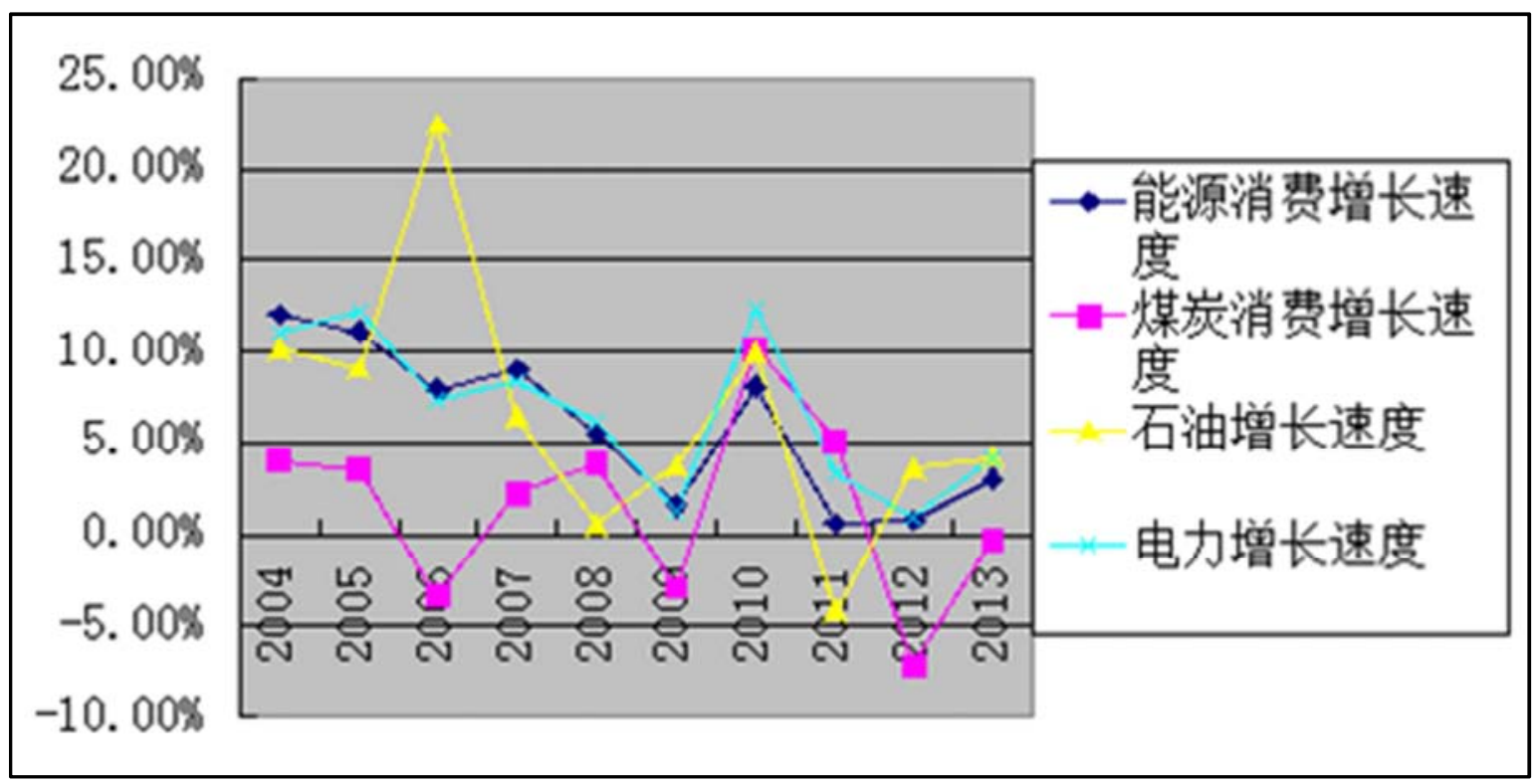

图2 2004-2013年能源增长速度趋势图。

2.3. 能源消的耗集中分布在第二产业

由下图可以看出能源集中分布在第二产业, 这是于上海作为中国甚至世界特大城市的地位是不匹配的。第二产业 属于高耗能产业, 如果上海不大力发展第三产业那么经济的增长即将是一种不可持续的非健康的道路。

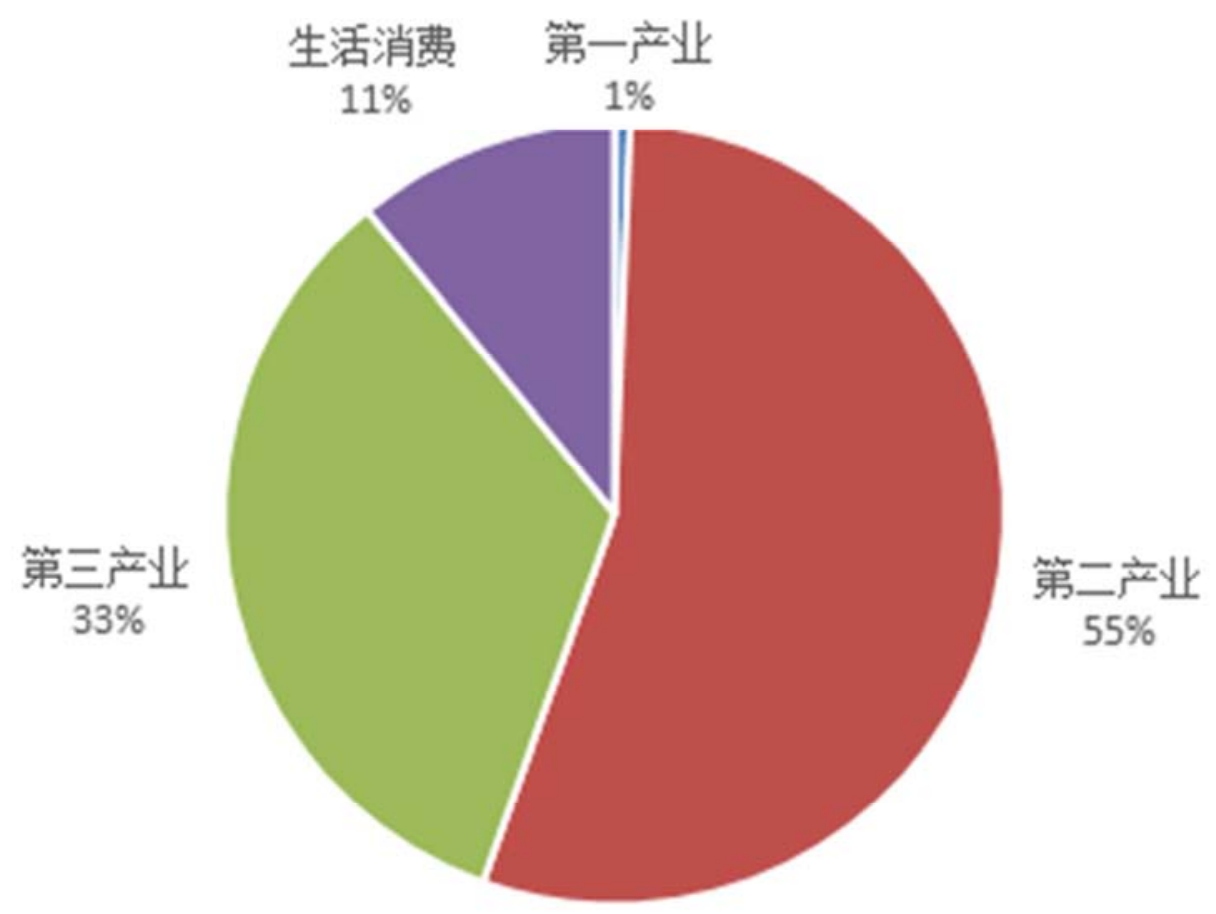

图3 以2013年为例各产业分布情况。

\section{4. 工业能源消费行业集中程度高}

上海工业重耗能行业集中在电子产品和汽车制造业, 石油化工及精细化工制造业，精品钢材制造业，成套设备 制造业和生物医药制造业。这六大行业占据了上海工业能 源消费的绝大部分 [3]。
3. 能源消费总量与经济增长的关系

3. 1. 能源消费强度与经济增长的关系

能源的消费强度是指单位地区生产总值消耗的能源 量, 即 


$$
e=\frac{E}{Y}
$$

其中E表示能源消费量，Y表示地区生产总值。

该指标说明一个国家经济活动中对能源的利用程度, 反映经济结构和能源利用效率的变化。一般用万元GDP能
耗和产品单位能耗来衡量。该指标一是直接反映经济发展 对能源的依赖程度。二是间接反映产业结构状况、设备技 术装备水平、能源消费构成和利用效率等多方面内容。三 是间接计算出社会节约能量或能源超耗量。四是间接反映 各项节能政策措施所取得的效果, 起到检验节能降耗成效 的作用。

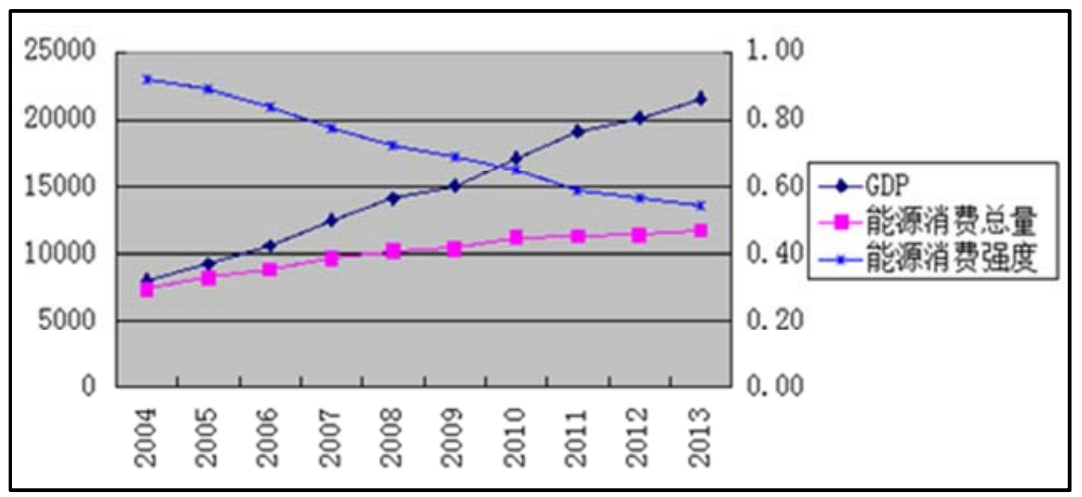

图4 上海市GDP与能源消费总量, 强度的变化趋势图。

由上图, 我们可以看出上海市单位GDP能耗不断下降 由 2004 年的 0.92 下降到 2013 年的 0.54 , 平均能源消费强度 0.60。在2004-2013年期间, 能源消耗增加, 经济增长快, 能源消费的增长速度小于经济的增长速度, 能源消费强度 出现平稳下降的态势。说明上海市产业结构不断调整, 促 进了经济的迅速发展, 提高了能源的利用率, 上海在追求 以消耗最少的能源获得最大的经济效益的过程中取得了 较好的效果。为了贯彻节能政策, 促进工业企业节能效果, 上海市采取了大力加强科技的投入, 调整产业结构等一系 列措施, 降低了能源消耗。

\section{2. 能源消费弹性系数与经济增长的关系}

能源消费弹性系数是反映能源消费增长速度与国民 经济增长速度之间关系的指标, 用两者年平均增长率的比 值表示。即

$$
\eta=\frac{\Delta E / E}{\Delta G / G}=\frac{\Delta E / \Delta G}{E / G}
$$

其中E表示能源消费总量, $G$ 表示经济总量, $\frac{\Delta E}{E}$ 表示 能源消费的增长速度, $\frac{\Delta G}{G}$ 表示经济增长速度, $\Delta E / \Delta G$ 表 示边际产值能耗, $E / G$ 表示单位产值能耗。

我们从能源弹性系数的计算公式中, 可以得到经济增 长速度、能源利用效率、边际产值能耗等因素的改变都能 影响到能源消费弹性系数的变化。通常用能源弹性系数来 反映经济增长速率与能源消费增长速度的相关性。由于受 科学技术水平、产业结构、产业规模等因素的影响, 能源 消费弹性系数波动较大。

从下图可以看出, 上海市能源消费弹性系数总体呈现 不断下降的趋势, 反映了经济发展对能源额依赖性越来越 低。在 2005 年弹性系数最大达到 0.97 , 此后不断下降, 在 2011年又达到高峰。2004-2013年平均弹性系数0.52, 说 明上海市的经济发展速度较快, 经济每增长一个百分点, 能源消费增长 0.5 个百分点左右。总之, 随着经济的迅速 发展, 科技水平的不断提高, 能源机构优化等措施的实施, 大大地提高了能源的利用效率, 从而降低了能源总量的消 耗。

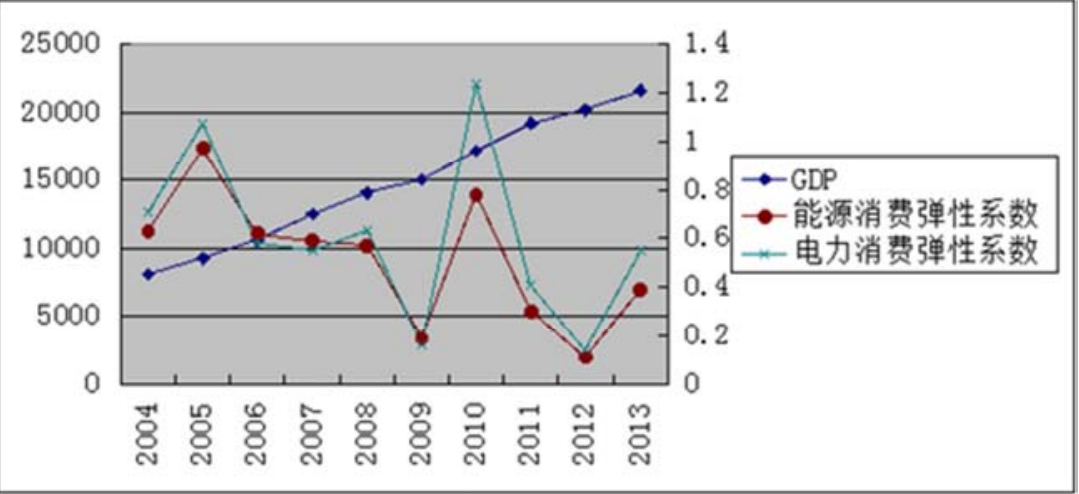

图5 GDP与能源, 电力消费弹性系数的变化趋势图。 


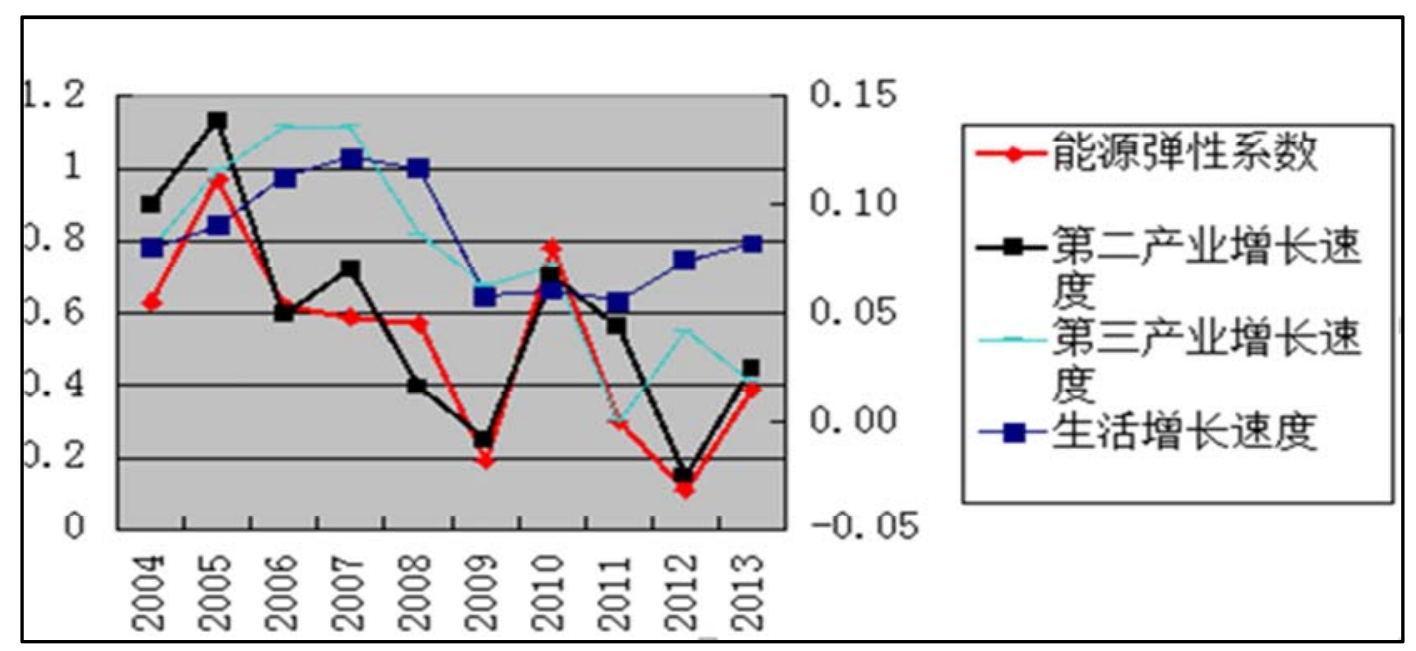

图6 弹性系数与第二三产业, 生活消费能耗增长速度趋势图。

从上图可以明显看出第二产业与能源消费弹性系数 高度相关, 2010年能源消费弹性系数的反弹是因为第二产 业的快速增长，而第二产业是高耗能产业，从而导致消费 弹性系数反弹。由下图可知, 上海市的五大产业的增长速
度和能源弹性系数呈现高度相关性, 并且五大产业属于第 二产业，有图6知第二产业在能耗消耗占三类产业中大部 分, 进而说明 2010 年能源弹性系数反弹是因为五大行业的 在2010年高速增长，带来了能耗的增长。

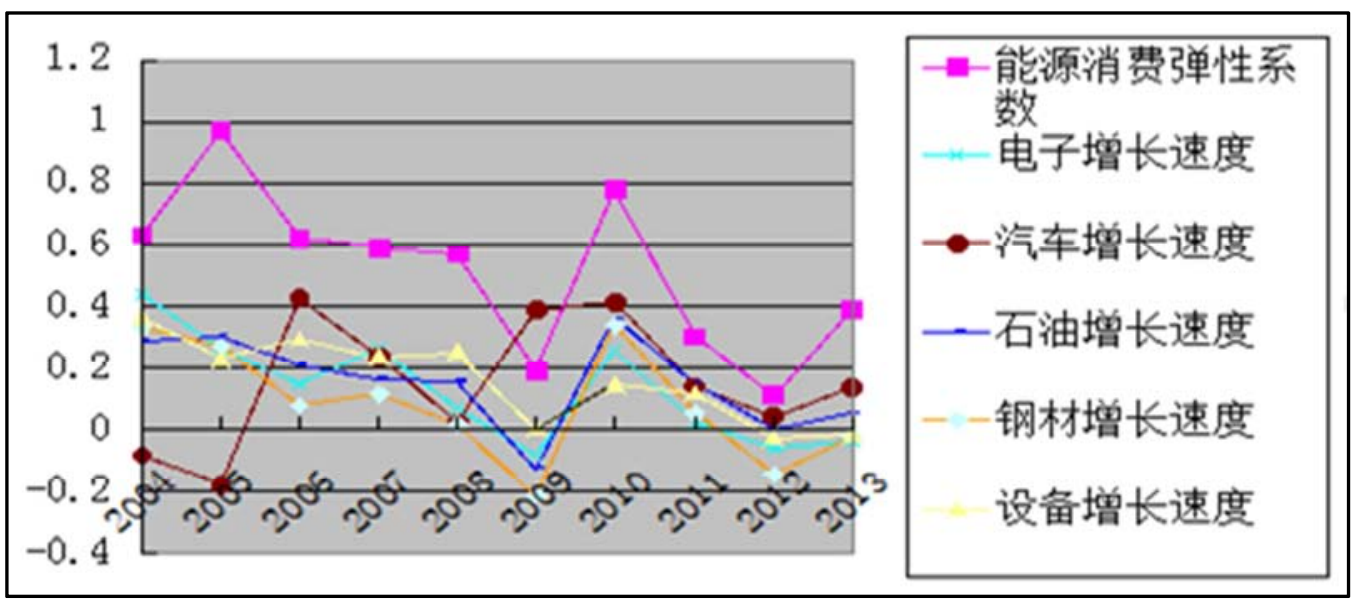

图7 能源消费弹性系数与五大产业产值增长速度趋势图。

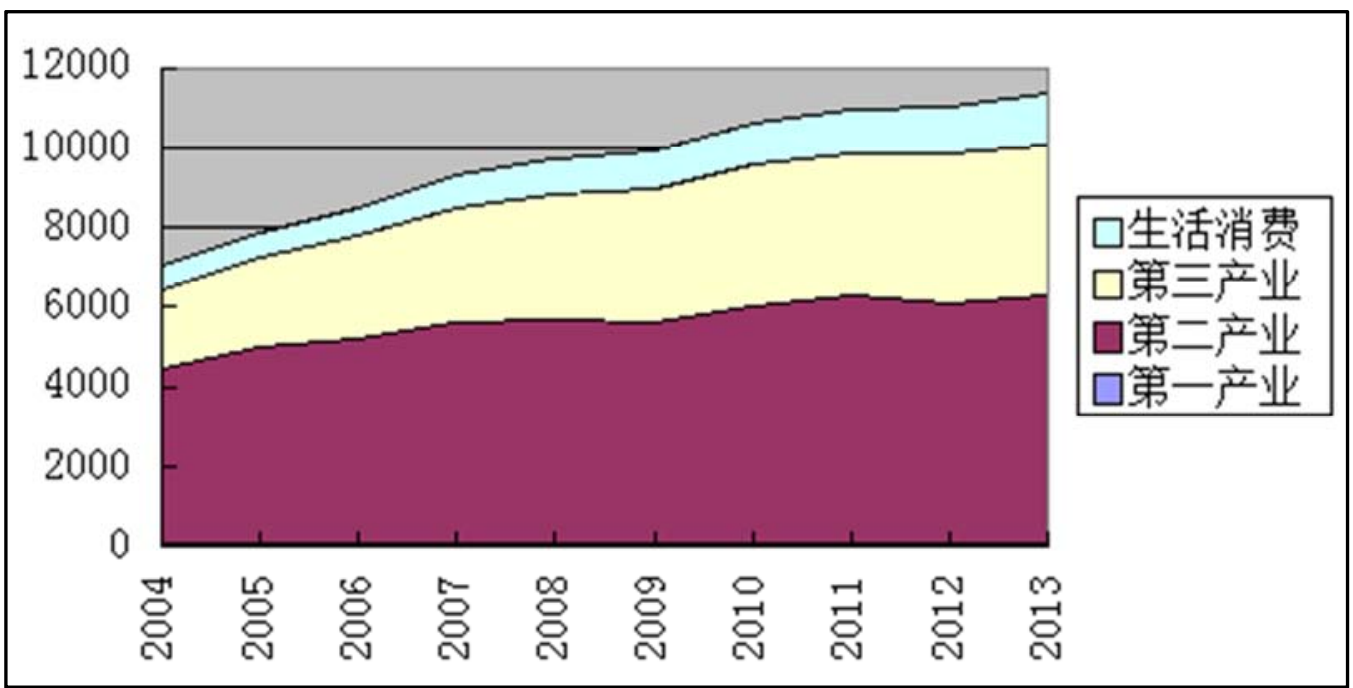

图8 三类产业, 生活消费能耗趋势图。 


\section{4. 能源消费结构与经济增长的灰色关联分析}

\section{1. 灰色关联分析介绍}

灰色系统理论是由中国的著名学者邓聚龙教授首创 的, 它一种系统科学理论 (Grey Theory), 是研究 “部分 信息已知，部分信息未知” 的不确定性系统 [4]。灰色关 联分析属于灰色系统理论中的一种分析方法, 作为一种系 统的分析技术, 它主要是一种分析系统中各个因素关联程 度的方法。其基本思想是通过序列曲线的几何形状的相似 程度来判断其联系是否紧密。如果曲线越接近, 则相应序 列之间的关联度越大，反之越小。以此就可以判断出引起 该系统发展的主要因素以及次要因素 [5]。该方法的特点 有:
(1) 克服了传统回归分析、主成分分析、方差分析等要 求的大量数据, 尤其是在中国统计数据十分缺乏, 而且通常现有的数据灰度比较大, 再加上种种人为 的原因, 数据经常会出现几次大起大落, 没有典型 的分布规律, 所以采用数理统计的方法往往难以奏 效。而灰色关联分析方法则可以弥补数理统计方法 作分析时所导致的缺陷;

(2) 计算量较小, 传统的统计分析一般需要高等计算机 才能完成，而且花费大量的时间;

(3) 灰色关联分析不会出现量化结果与定性分析结果 不相符的现象 [6]。但主要缺点在于要求需要对各 项指标的最优值进行现行规定, 出现主观性过强, 同时存在着部分指标最优值难以确定的问题。

表1 2004-2013年能源消费与经济增长的关联系数、关联度。

\begin{tabular}{|c|c|c|c|c|c|c|c|c|c|c|c|}
\hline \multirow{2}{*}{ 变量 } & \multicolumn{10}{|c|}{ 关联系数 $r$} & \multirow{2}{*}{ 关联度 } \\
\hline & 2004 & 2005 & 2006 & 2007 & 2008 & 2009 & 2010 & 2011 & 2012 & 2013 & \\
\hline$X(1)$ & 1 & 0.88 & 0.72 & 0.60 & 0.54 & 0.49 & 0.44 & 0.40 & 0.36 & 0.33 & 0.57 \\
\hline$X(2)$ & 1 & 0.93 & 0.97 & 0.86 & 0.71 & 0.67 & 0.61 & 0.49 & 0.47 & 0.44 & 0.72 \\
\hline$X(3)$ & 1 & 0.97 & 0.88 & 0.70 & 0.69 & 0.63 & 0.59 & 0.51 & 0.48 & 0.45 & 0.69 \\
\hline
\end{tabular}

\section{2. 其主要的建立方法为}

（1）建立系统的序列, 包括原始数列的因变量参考数列 和自变量的比较数列

因变量参考数列为 $x_{0}(t)$

$$
x_{0}(t)=\left\{x_{0}(1), x_{0}(2), \ldots x_{0}(t)\right\} \quad(t=1,2,3 \ldots)
$$

自变量比较数列为 $x_{i}(t)$

$$
x_{i}(t)=\left\{x_{i}(1), x_{i}(2), \ldots x_{i}(t)\right\} \quad(i=1,2,3 \ldots)
$$

（2）量纲处理。由于在系统中存在着各因素的物理意义 不同, 从而导致数据的量纲也不一定相同, 这就会 影响到关联度的计算结果, 进而失去了比较的意义。 为了能够消除量纲影响, 增加不同量纲因素之间的 可比性, 首先需要对各因素的最初数据作初值变换。 初值变换公式为

$$
x_{i}^{\prime}(t)=\frac{x_{i}(t)}{x_{i}(1)} \quad(i=0,1,2,3 \ldots)
$$

(3) 计算关联系数

$$
\begin{aligned}
& r(t)= \\
& \frac{\min _{i} \min _{t}\left|x_{0}(t)-x_{i}(t)\right|+k \cdot \max _{i} \max _{t}\left|x_{0}(t)-x_{i}(t)\right|}{\left|x_{0}(t)-x_{i}(t)\right|+k \cdot \max _{i} \max _{t}\left|x_{0}(t)-x_{i}(t)\right|}
\end{aligned}
$$

(4) 计算关联度

$$
R=\frac{1}{n} \sum_{i=1}^{n} r(t)
$$
度越大。

$\mathrm{R}$ 即为关联度系数, 其越接近与 1 说明两者之间的关联

\section{3. 灰色关联分析应用}

以2004-2013年上海市的的GDP为 $\mathrm{x}(0)$ 参考数列 [7], 煤炭消费量 $\mathrm{x}(1)$ 、石油消费 $\mathrm{X}$ (2) 和电力消费量 $\mathrm{X}$ (3) 为比较 数列, 运用灰色关联分析方法, 分析上海市能源消费结构 与经济增长的相关性 [8]。

从表 1 分析中我们可以得知, 能源消费总量与经济发 展关联度很高, 煤炭、石油及电力消费对经济的发展有极 大的促进作用。随着经济发展、科技的进步, 能源消费与 经济增长的关联系数逐年降低。其中, 石油消费量与经济 增长的关联度最大, 其次是电力, 最后是煤炭。这说明上 海市经济的发展对石油、电力的需求逐渐增强。

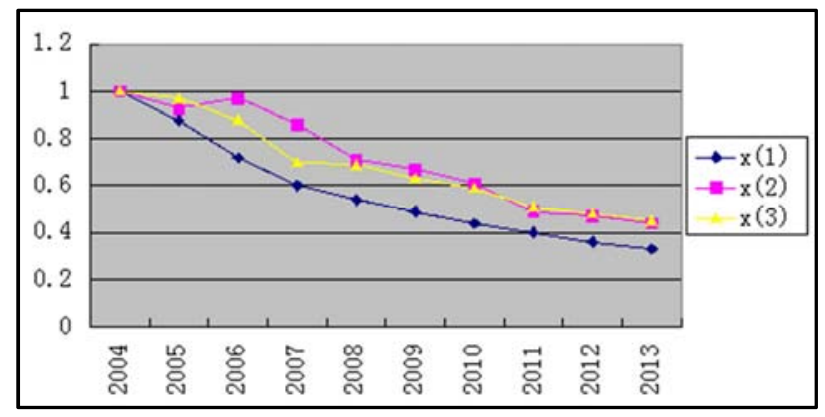

图9 各关联系数趋势图。

由于煤炭是高污染能源, 所以上海必定会逐步淘汰煤 炭的消费, 而对于电力这种二次能源不能完全代替化石燃 料, 且电力价格远高于其他能源, 所以综合来看石油与经 济增长的关系最密切 [9]。 


\section{5. 上海市的可持续发展对策}

\section{1. 优化能源的消费结构}

应积极地开发新能源和可再生能源的多样化与可替 代化是能源消费可持续发展的出发点 [11]。目前上海市的 能源结构中, 消费主体是煤炭和石油, 而天然气所占比重 比较低, 这样的能源消费结构与上海国际化大都市的身份 是不匹配的。

今后的能源消费中, 不仅要与一些煤炭资源大省进行 战略合作, 同时要逐步减轻对煤炭的依赖, 到达减少对环 境的污染, 而且要做好石油的战略性储备和风险控制, 减 小海运运输石油或国际市场原油价格波动中存在对上海 经济的风险。

此外, 今后能源发展的主流方向是开发新能源和可再 生能源, 所以要加强天然气的生产与利用, 努力增加可再 生能源如潮汐能、水能等的研发等等, 进而有效地减轻污 染，提高环境效益、经济效益和社会效益。

\section{2. 合理地利用能源, 建立节约型社会}

随着中国居民生活水平的不断提高, 对能源的需求也 迅速增加。从长远发展的角度来看, 提高生活质量不能以 能源的过渡消耗为代价, 必须合理的利用能源, 坚持科学 的发展观，在全社会形成节约能源的良好社会风气[12]。

所以, 我们倡导的可持续的发展, 也即能源消费与经 济发展相协调的发展可以首先在一些学校、大型企业、政 府机关等单位和机构推广节能减排计划, 加大对广大公民 的宣传教育，提高公民的社会责任感和节能意识。

尝试征收的环境税, 环境税又被称绿色税或生态税, 是把生态破坏和环境污染的社会总成本内化到生产成本 与市场价格当中, 再通过社会主义市场机制来重新分配环 境资源。在目前欧盟强制征收碳关税的背景下，上海可以 尝试首先征收碳税 $[13]$ 。

\section{3. 进一步优化产业结构, 提高经济增长的质量}

虽然上海经济保持了许多年的高速度增长, 但在某种 程度上仍然是依靠高强度的资源大量投人才得以实现, 倘 若未来继续保持之前的增长方式, 以能源角度看几乎难以 维系。如果要实现能源消费的可持续性发展和实现经济的 高质量高效益必须做到:

(1) 应更进一步提高能源消耗低与附加值高的服务业 比重。

(2) 对能源消费主要的工业其内部进行调整, 要发展以 高新科技为代表的低能耗和低污染的技术密集型 的行业。

（3）对重要的高能耗产业要调整产品结构, 如石化等基 础行业, 以降低单位产品的能耗和高端材料为突破, 从而提高产品的技术含量与附加值。

(4) 严格制定并实施产业分类的指导计划。以污染排放、 单位增加值的能源消耗为基础，同时参考就业贡献 率、税收率等指标，制定产业的分类指导目录。对 于那些符合上海节能减排目标与发展目标的战略 性优势产业和新兴产业，制定引导和鼓励性的产业
政策, 从而促进这些产业的迅速发展; 对于那些相 对劣势产业，应制定鼓励产业转移或退出、产业升 级的系统性政策; 对于那些环境污染和能源消耗严 重, 但又不影响国计民生的产业, 应对已有企业规 定做最后期限, 同时, 实行强制的淘汰禁止投资新 项目。

（5）实施能源的排污权交易、碳排放交易 [14]。根据上 海环境承受能力以及节能减排的指标, 应制定严格 的环境指标体系。同时，应根据上海市的实际情况， 推行强制碳排放交易与排污权交易。近期的首要任 务是：尽快制定交易制度和交易规则，尽早推出碳 排放交易和排污权交易。主要利用市场化的手段, 鼓励相关企业努力做好节能减排的工作。

\section{4. 以科技进步为导向, 提高能源利用的效率}

目前中国已逐步融人世界经济全球化进程中，因此必 须积极地去承接一些产业转移, 这其中有很大一部分是能 源消费较大的产业, 这就要求我们必须坚定不移地依靠科 技进步，通过技术创新提高能源的利用效率 [15]。首先， 必须多渠道地加大科研方面的投入强度, 提高能源利用中 的科技含量, 落实降低能耗的重要项目, 从而实现用低水 平的能源消费满足经济的快速发展, 能源消费和资源、环 境的发展相协调; 还要通过技术的努力创新提高产业技术 含量和产品的附加值, 进而提高单位能耗下的产出。

\section{5. 以优化产业空间布局, 促进产业集中与集聚}

对于实现节能减排的总的目标，上海的产业空间布局 优化、产业的集中、制造业链的整合、生态工业园区的构 建, 都可以起到十分重要的作用 [16]。

产业的集中不仅可以在某种程度上实现众多企业的 集中供能或供热以及集中处理污染物, 还能有效地循环 利用各种副产品和废弃物, 提高资源利用效率。于不同 的产业部门, 可以实行不同的生态化集中与集聚方式 [17]。如对于化工产业, 可以构造以产品链为导向的生 态化工园区; 至于钢铁行业, 可以构建副产品和废弃物 等综合利用为特征的大型混合型钢铁工业园; 对于汽车 行业, 可以构建以生态供应链等为特征的汽车城; 对于 电子通信产业, 可以构建以污染物等集中处理为特点的 高新技术产业园。

\section{6. 结论}

通过分析得出, 上海市的经济增长与能源消费的增长 具有一定的关联性, 且与石油的关联性最高, 但随着经济 的发展能源与经济增长的关联性逐步减低。第二产业作为 高耗能产业, 其高速发展必然带动能源消耗的增长, 从文 中分析可以得出, 如果要继续减低能源消耗强度, 应大力 发展第三产业。上海作为中国改革开放前沿, 其经济位于 中国前列, 其经济发展对于中国未来的经济发展具有十分 重要的指导意义, 因此中国提高能源利用率必须加大技术 投入, 减低能源强度必须大力发展第三产业, 优化产业结 构。 


\section{参考文献}

１１）钟爽, 李国柱, 张潞. 吉林省能源消费与经济增长关系的有 研究 $[J]$. 中国人口资源与环境, 2014（11）：41４4。

[2] 刘宏杰. 中国能源消费与经济增长之间的关系 $[J]$. 华北电 力大学学报 (社会科学版), 2007, (4)：19～22。

[3] 梁日忠. 上海市经济增长与能源结构, 产业结构关联状况 的评价研究 $[J]$. 华东经济管理, 2014（1）：42 46。

４4］尹春华, 顾培亮. 我国产业结构的调整与能源消费的灰色关 联分析 [J]. 天津大学学报, 2003 (1)：104 107。

[5] 王否, 吕璐, 解明明. 经济增长、结构变迁与中国能源消费 [J]. 华东经济管理，2012，26（8）：59～65。

[6] 王中英, 王礼茂. 中国经济增长对碳排放的影响分析 [J]. 安全与环境学报, 2006, 5（1）：88９1。

[7] 正张, 欢勇. 灰色系统建模理论与应用 [D]. 浙江, : 浙江理工 大学, 2008。

[8］刘爱芹. 山东省能源消费与工业经济增长的灰色关联分析 [J]. 中国人口资源与环境，2008（3）：103 107。

［9］姚政，郝传波. 黑龙江经济增长与能源消费结构变动实证 分析 $[\mathrm{J}]$. 能源与环境, $2007,(4)$ ： 18 19。

[10] 刘思峰, 党耀国, 张歧山. 灰色系统理论及其应用 (第三 版) [M]。北京：科学出版社, 2004。

[11] 唐忆文, “十二五” 期间上海能源发展的新形势与新举措 [J]. 电力与能源, 2012, (6) : 187 202。

[12] 张鹏伟. 河南省物流发展影响因素的灰色关联分析 [J]. 生 产率研究, 2011, (6) : 75 82。

[13] 陈建宏, 王文哲, 熊汉富. 湖南省排放因素的灰色关联分析 $[J]$. 地域研究与开发，2010，（8）：131～134。

[14] 宋涛, 郑挺国. 环境污染与经济增长之间关联性的理论分析 和计量检验 $[\mathrm{J}]$. 地理科学，2017，27（11）：156～162。

[15] 冬锋, 谭清美. 技术进步, 产业和对外开放程度对中国能源 消费量的影响——基于灰色关联分析协整检验两步法的实 证 $[J]$. 中国人口资源与环境，2010，6（11）：163～168。

[16] 于凤玲, 陈建宏. 基于灰色关联与优势分析的能源消费与工 业环境污染的实证研究 $[J]$. 环境污染与防止, 2012, 11: $65 \sim 77$ 。

[17] 环常军乾, 徐凯. 21实际我国主要能源消费的灰色关联研究 [J]. 中国矿业, 2010，1：57〜65。 